\title{
HISTOLOGICAL EVALUATION OF THE EFFECT OF LASER AND ULTRASOUND ON BONE FRACTURE HEALING
}

\author{
May F. Al-Habib ${ }^{1}$, Imad M. Al-Ani ${ }^{2}$, Mohammad O. Salman ${ }^{3}$ and Farah W. Faleh ${ }^{4}$ \\ ${ }^{1}$ Department of Anatomy, College of Medicine, Al-Nahrain University, Baghdad, Iraq, \\ ${ }^{2}$ Department of Basic Medical Science, Kulliyyah of Medicine, International Islamic \\ University Malaysia, Kuantan, Pahang, Malaysia, ${ }^{3}$ Department of Applied Embryology, \\ High Institute of Infertility Diagnosis and ART, Al-Nahrain University, Baghdad, Iraq, \\ ${ }^{4}$ College of Medical Engineering, Al-Nahrain University, Baghdad, Iraq.
}

Presenter: Imad M. Al-Ani, imadmatloub@iium.edu.my

Objective: To study the effect of both laser and ultrasound radiation on bone fracture healing process.

Materials and method: Nd:YAG laser (1064 nm wavelength, $135 \mathrm{~mW}$ power, 16 joules energy) and ultrasound ( $1 \mathrm{MHz}$ frequency, $50 \mathrm{~mW} / \mathrm{cm} 2$ power intensity) were used in this work. Fifteen mature, male, albino rats were divided into three groups and subjected to a partial fracture on the lateral aspect of femur by a sharp blade. The first group of these animals served as the control group. The second group was illuminated by the Nd:YAG laser for two minutes, the first dose was given immediately after surgical fracture induction, the other doses were given on days two, three, six and then one dose weekly for the next three weeks. The third group was treated with the addition of continuous wave ultrasound perpendicular to the laser treatment site in the second group.

Results: The histological assessments at day 28 after the fracture of first group showed incomplete healing of the bone with disfiguration and disarrangement of Haversian system and the periosteum was not yet well developed. Treatment with laser in the second group showed irregularity and lack of Haversian system formation in bone healing. The laser and ultrasound treatment in the third group expressed a complete healing at the site of fracture with a complete layer of periosteum and a well arranged Haversian system.

Conclusion: The combination of laser and ultrasound in therapy can enhance healing process of a fractured bone more than laser therapy alone, as ultrasound increases the depth of laser penetration in tissue. 